\begin{tabular}{l} 
JOURNAL OF EMPOWERMENT \\
VOL. 2, No. 2, Desember 2021, h. 210-222 \\
ISSN 2580-0620 (Print) \\
ISSN 2597-9809 (Online) \\
Available Online at https://jurnal.unsur.ac.id/index.php/JE \\
\hline \hline
\end{tabular}

\title{
PENGABDIAN KEPADA MASYARAKAT MENGENAI PEMANFAATAN SISTEM INFORMASI PENJUALAN RUMAH BERSUBSIDI BERBASIS ONLINE
}

\section{SERVICE TO THE COMMUNITY REGARDING THE UTILIZATION OF ONLINE-BASED HOUSE SALES INFORMATION SYSTEMS}

\author{
'Muhamad Syarif, 2 Latifah, ${ }^{3}$ Ardiyansyah, ${ }^{4}$ Wahyu Nugraha \\ 1234 Universitas Bina Sarana Informatika \\ muhamad.mdx@bsi.ac.id, latifah.lat@bsi.ac.id \\ ardiyansyah.arq@bsi.ac.id, wahyu.whn@bsi.ac.id
}

\begin{tabular}{|l|l|l} 
Masuk: 18 Oktober 2021 & Penerimaan: 04 Desember 2021 & Publikasi: 31 Desember 202
\end{tabular}

\begin{abstract}
ABSTRAK
Penerapan sistem informasi berbasis komputer yang belum sepenuhnya optimal diterapkan pada PT. Jiwa Properti Indah seperti pencatatan administrasi, pembuatan laporan pemesanan rumah, pencatatan data konsumen dan pembuatan laporan penjualan. Minimnya pengetahuan mengenai pemanfaatan sistem informasi pada PT Jiwa Properti Indah yang menjadi mitra pengabdian kepada masyarakat menjadi sebab kami sebagai pihak akademisi untuk terus terlibat dan mendorong pemanfaatan teknologi informasi. Mitra pengabdian menunjukkan antusias dan respon yang baik terhadap kegiatan untuk peningkatan pengetahuan dalam pemanfaatan dan penerapan sistem informasi di perusahaannya. Kegiatan pengabdian masyarakat telah dilaksanakan mulai dari sosialisasi mengenai cara penggunaan aplikasi berdasarkan dokumentasi aplikasi hingga simbolis serah terima aplikasi.
\end{abstract}

Kata Kunci : Informasi; Perusahaan; Penjualan; Online.

\begin{abstract}
The application of a computer-based information system that is not yet fully optimal is applied to PT. Jiwa Properti Indah such as administrative records, making home order reports, recording consumer data and making sales reports. The lack of knowledge about the use of information systems at PT Jiwa Properti Indah which is a community service partner is the reason for us as academics to continue to be involved and encourage the use of information technology. Service partners show enthusiasm and good response to activities to increase knowledge in the use and application of information systems in their companies. Community service activities have been carried out starting from socializing on how to use applications based on application documentation to symbolic handing over of applications.
\end{abstract}

Keywords : Information; Company; Sale; Online.

\section{A. PENDAHULUAN}

Memasuki era revolusi industri 4.0 Teknologi Informasi dan Komunikasi (TIK) mengalami perkembangan yang pesat dan mempengaruhi kehidupan manusia (Savitri, 2019). Pengaruh perkembangan internet dan teknologi digital yang sangat masif menyebabkan semua hal menjadi tanpa batas (borderless) dengan penggunaan data yang tidak terbatas (unlimited) pula (AI Yakin, 2019)(Suwandi, 2019). Semakin canggih teknologi maka semakin mendorong para pemilik perusahaan untuk mencari inovasi dalam mengembangkan perusahaannya agar bisa diketahui oleh seluruh lapisan masyarakat dalam memasarkan produknya (Hermawanto \& Anggraini, 2020). 
Pesatnya perkembangan teknologi dari masa ke masa ditandai dengan munculnya inovasi-inovasi yang ada seperti perangkat pintar yang bisa dibawa kemana-mana dalam genggaman tangan (A Purba et al., 2020). Adanya perkembangan teknologi memudahkan kegiatan sehari-hari di perusahaan serta menghemat waktu. Contoh perkembangan teknologi dalam pengiklanan rumah selain melalui media baliho atau pamflet bisa diiklankan dalam web yang membuat jangkauan pemasarannya menjadi lebih luas (Sidik \& Rahmawati, 2018). Perubahan sistem pencatatan secara manual dengan menggunakan media kertas menjadi terkomputerisasi dalam perusahaan bisa terjadi dengan adanya dukungan dari perkembangan teknologi (Beben Sutara, 2017). Sistem yang terkomputerisasi dapat mengolah data dalam waktu yang singkat dan akurat dengan menggunakan teknologi yang bisa mengolah data menjadi informasi yaitu sistem perangkat lunak (software) (Nugraha \& Syarif, 2018).

PT Jiwa Properti Indah merupakan suatu badan usaha milik swasta yang berdiri dalam bidang perdagangan, real estate dan properti, serta membangun dan menjual perumahan bersubsidi dari pemerintah yang ditujukan untuk masyarakat berpenghasilan rendah. Pencatatan administrasi, pembuatan laporan pemesanan rumah, pencatatan data konsumen dan pembuatan laporan penjualan pada PT Jiwa Properti Indah masih dicatat di dalam buku dan pada akhir bulan data tersebut dipindahkan ke Ms. Excel. Maka dari itu, masalah yang sering dialami oleh PT Jiwa Properti Indah yaitu mengalami keterlambatan dalam pembuatan laporan penjualan rumah.

Latar belakang masalah di atas mendorong kami untuk melaksanakan kegiatan pengabdian masyarakat di perusahaan yang bergerak di bidang properti perumahan dan merancang sistem terkomputerisasi berbasis web dengan harapan setelah sistem informasi penjualan ini selesai dibuat dan diterapkan dapat mengatasi masalah yang dialami oleh perusahaan tersebut.

\section{B. METODE}

Adapun metode yang dilakukan adalah dengan menghibahkan website sekaligus memberikan pelatihan terhadap penggunaan dan bagaimana pemanfaatan Website Penjualan Rumah Kpr-Btn Bersubsidi Pada PT. Jiwa Properti Indah Pontianak yang dilaksanakan secara offline dengan merapkan protokoler kesehatan. Diharapkan dengan di aplikasikannya website tersebut, maka mitra dapat memaksimalkan pemanfaatan dan penjualan rumah KPR-BTN Bersubsidi Pada PT. Jiwa Properti Indah Pontianak. Metode pelaksanaan yang kami lakukan tergambar melalui diagram di bawah ini.

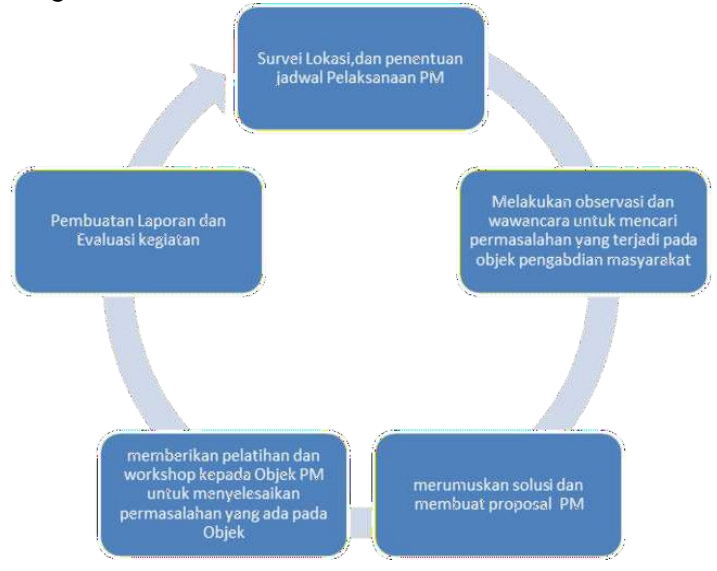

Gambar 1. Alur Metode Pelaksanaan PM 
Pelaksanaan kegiatan pengabdian masyarakat dilaksanakan pada: Hari : Sabtu

Tanggal

Lokasi

Tim Pengabdian
: 2 Oktober 2021

: Kantor PT. Jiwa Properti Indah Pontianak JI. Sepakat Ruko No 3 Pontianak

: Muhamad Syarif, M.Kom Tutor; Ardiyansyah, M.Kom; Latifah, SE, MM; Wahyu Nugraha, M.Kom

\section{HASIL ATAU PEMBAHASAN}

Hasil dari kegiatan pengabdian kepada masyarakat ini ialah peningkatan pengetahuan dan pemanfaatan teknologi informasi berupa pemanfaatan Sistem Informasi Penjualan Rumah Kpr-Btn Bersubsidi Berbasis Web Pada PT Jiwa Properti Indah Pontianak.

Tingkat pemahaman dan penerapan sistem informasi mitra sebagai UMKM masih tergolong rndah, hal ini berdasarkan hasil wawancara terhadap mitra. Setelah dilakukan diskusi, pemaparan sistem berjalan yang diterapkan saat ini, hasil survey serta pemaparan yang disampaikan oleh mitra, maka dibuatlah sistem informasi Penjualan Rumah Kpr-Btn Bersubsidi Berbasis Web yang melibatkan dosen IT, amanjemen serta mahasiswa Universitas bina Sarana Informatika kampus Kota Pontianak. Kemudian teknologi yang telah di buat di hibahkan kepada mitra agar dapat diimplementasikan untuk menunjang kegiatan mitra agar lebih efektif dan efisien.

Dengan pemanfaatan teknologi informasi ini, diharapkan website penjualan rumah ini dapat menjadi salah satu solusi yang bisa digunakan untuk mempermudah dalam mengelolah data penjualan serta dapat membuat laporan penjualan dengan cepat dan efisien oleh mkitra maupun masyarakat sebagai konsumen yang mencari rumah subsidi KPR. Aplikasi penjualan yang di rancang dapat di akses oleh konsumen, admin marketing, admin keuangan, dan direktur agar dapat menjadi sebuah sistem yang saling brkaitan dan mempermudah proses pengelolaan keuangan, penjualan, promosi, administrasi maupun laporan. Gambaran Iptek yang diimplentasikan di Mitra sasaran yaitu aplikasi website penjualan rumah. Dalam pemakaian aplikasi penjualan ini dapat memudahkan pekerjaan dan dapat mengurangi kesalahan dalam mengelola data penjualan rumah. Aplikasi penjualan ini dapat menyimpan serta mencetak data sehingga data penting konsumen dan perusahaan dapat tersimpan dengan aman.

Berikut adalah user interface dari website yang berhasil dirancang mengunakan framework bootstrap (Spurlock, 2013), dan kemudian dihibahkan kepada mitra untuk membantu kegiatan usaha mitra :

1. User Interface Halaman Utama

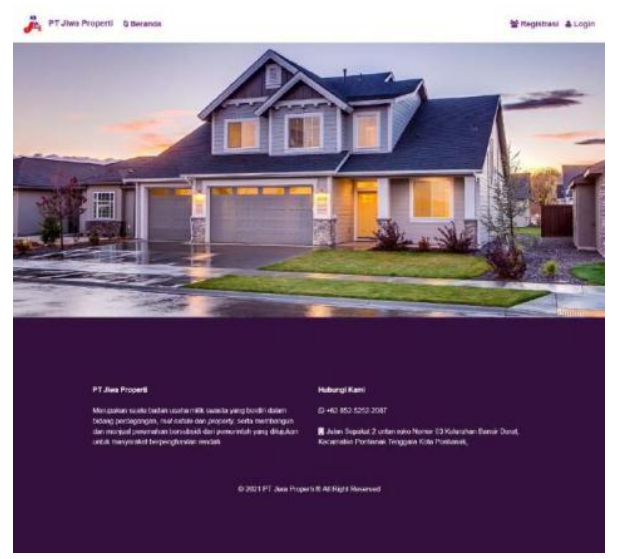

Gambar 2. User Interface Halaman Utama 
2. User Interface Halaman Form Data Konsumen

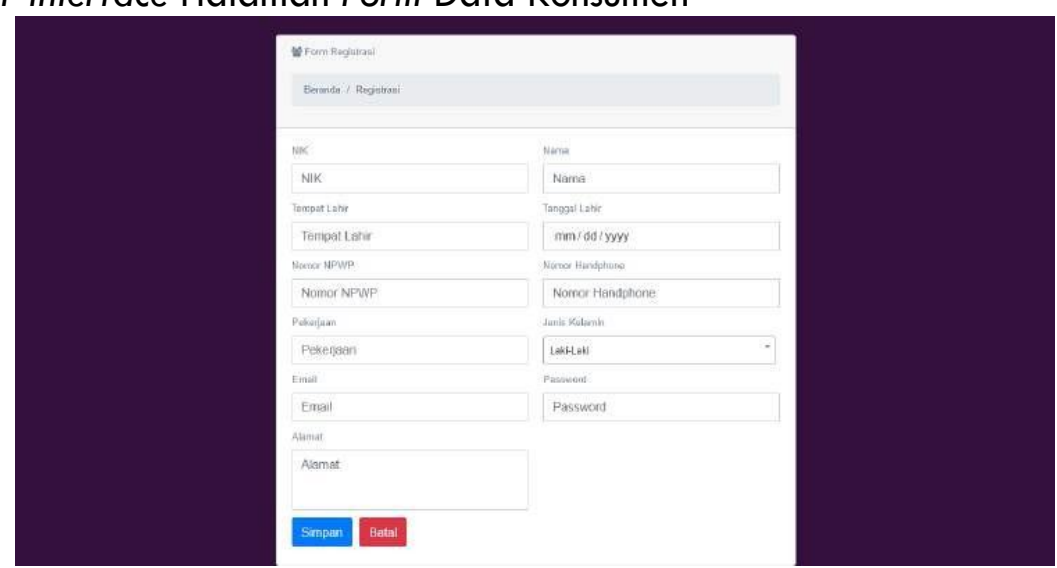

Gambar 3. User Interface Halaman Form Data Konsumen

3. User Interface Halaman Login

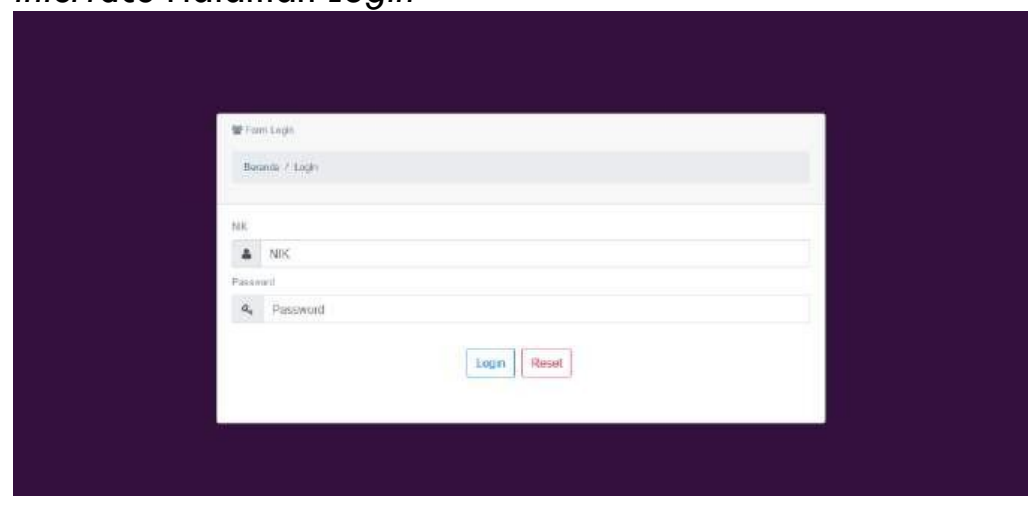

Gambar 4. User Interface Halaman Login

4. User Interface Halaman Beranda Konsumen

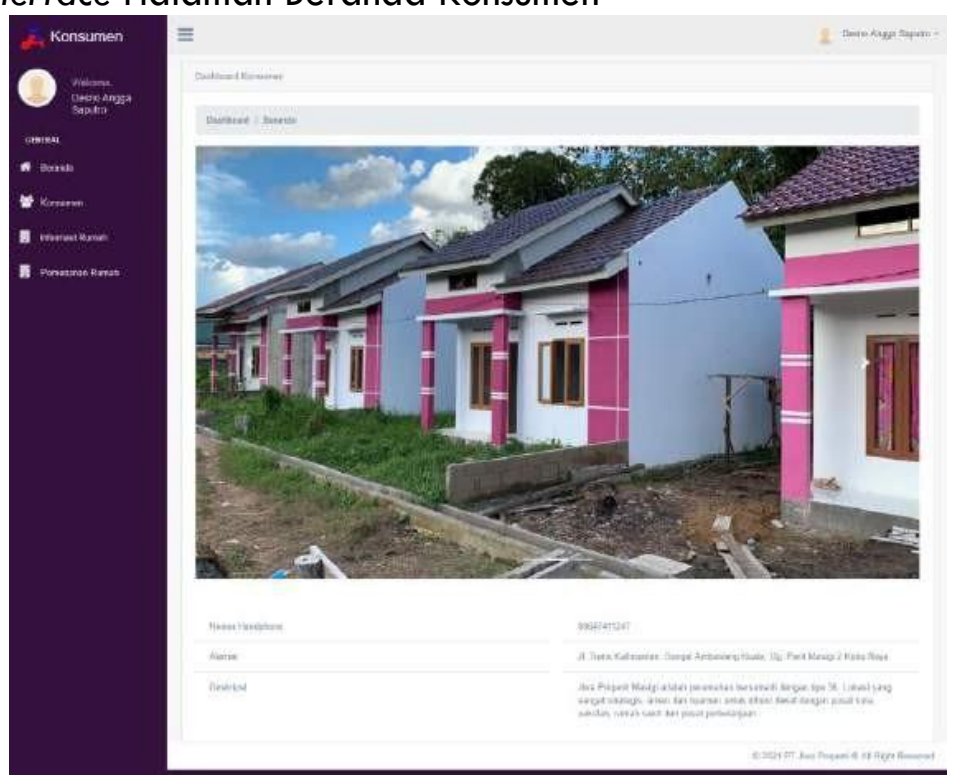

Gambar 5. User Interface Beranda Konsumen 
5. User Interface Halaman Data Konsumen

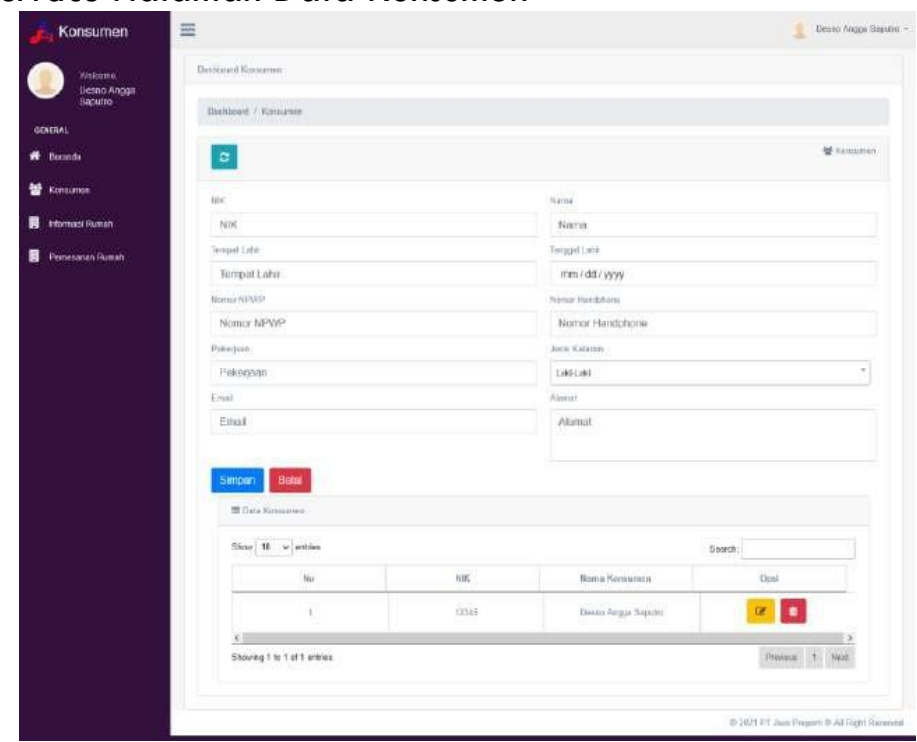

Gambar 6. User Interface Halaman Data Konsumen

6. User Interface Halaman Data Informasi Rumah

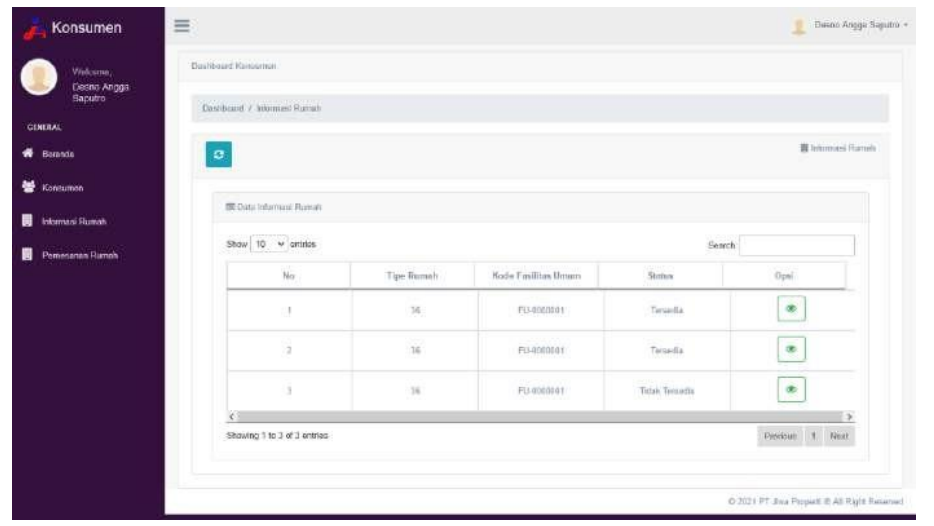

Gambar 7. User Interface Halaman Data Informasi Rumah

7. User Interface Halaman Data Pemesanan Rumah

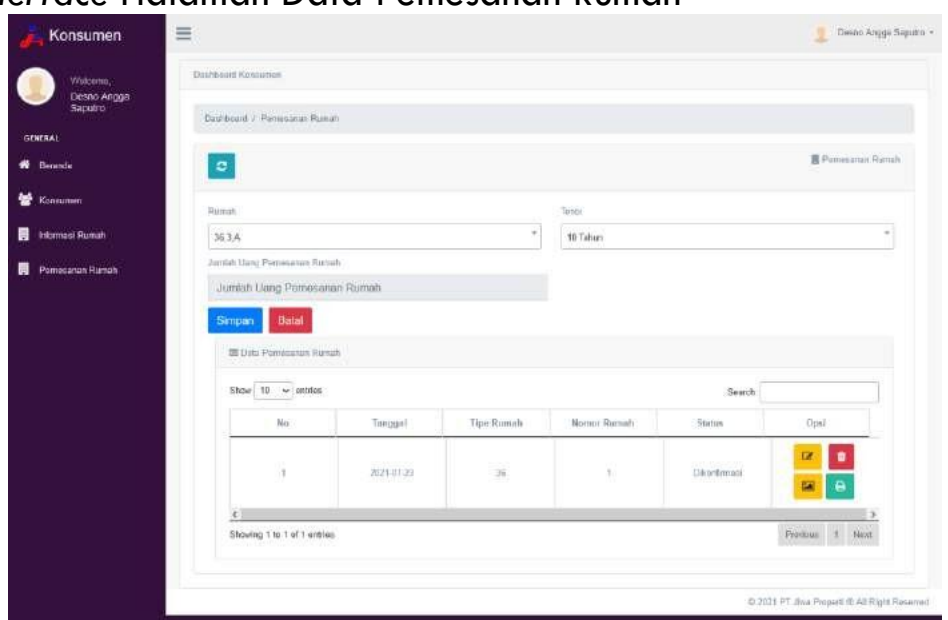

Gambar 8. User Interface Halaman Data Pemesanan Rumah 


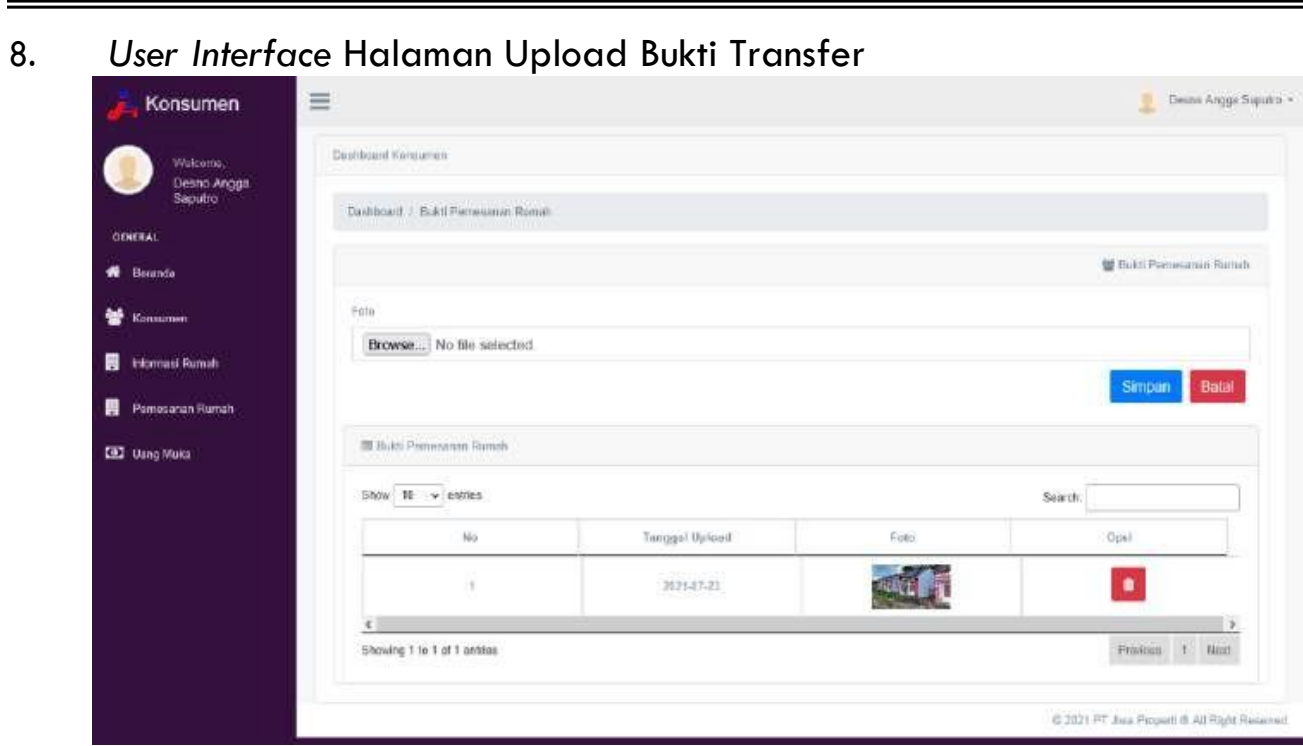

Gambar 9. User Interface Halaman Upload Bukti Transfer

9. User Interface Halaman Beranda Admin Marketing

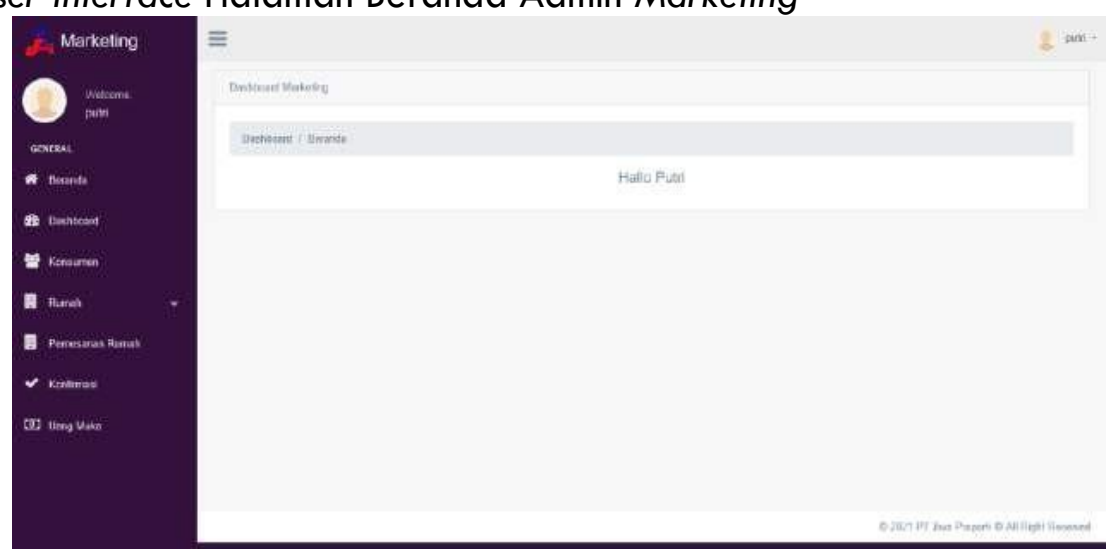

Gambar 10. User Interface Halaman Beranda Admin Marketing

10. User Interface Halaman Dashboard

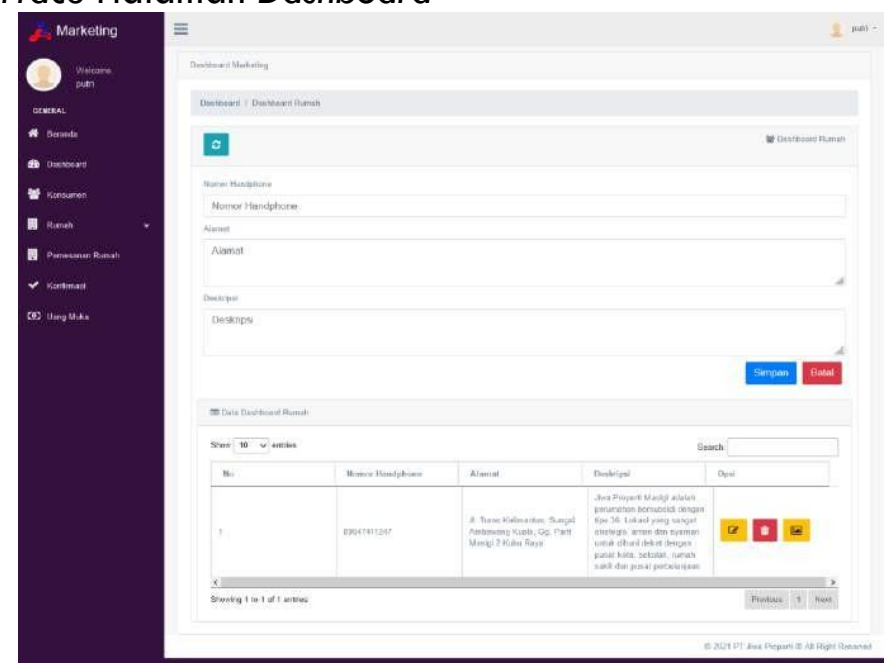

Gambar 11. User Interface Halaman Dashboard 
11. User Interface Halaman Upload Foto Dashboard

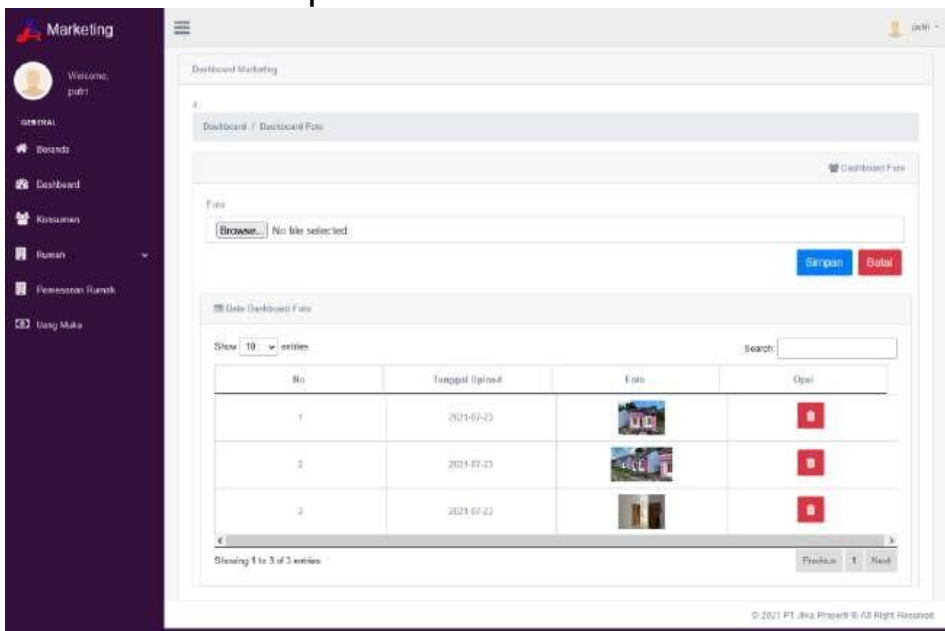

Gambar 12. User Interface Halaman Upload Foto Dashboard

12. User Interface Halaman Data Konsumen

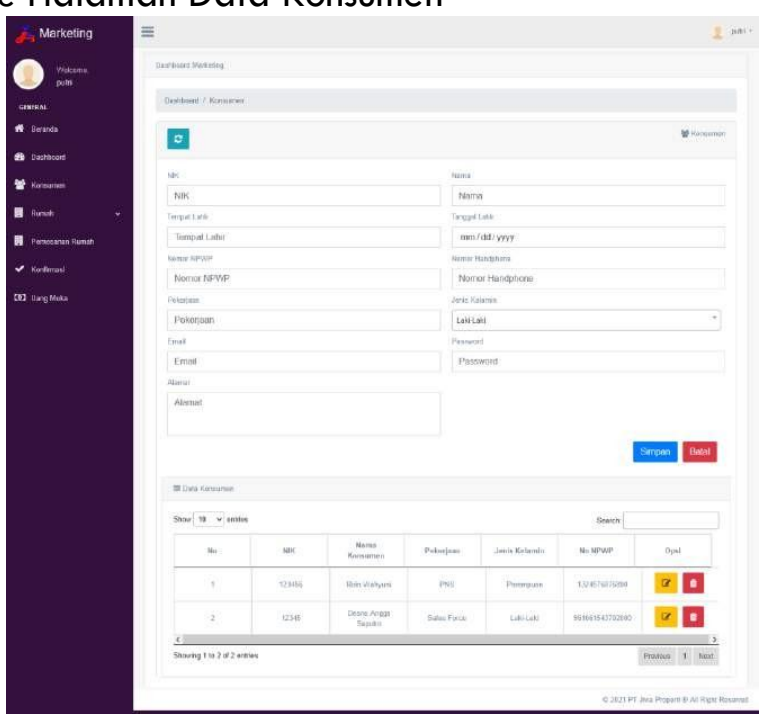

Gambar 13. User Interface Halaman Data Konsumen

13. User Interface Halaman Tipe Rumah

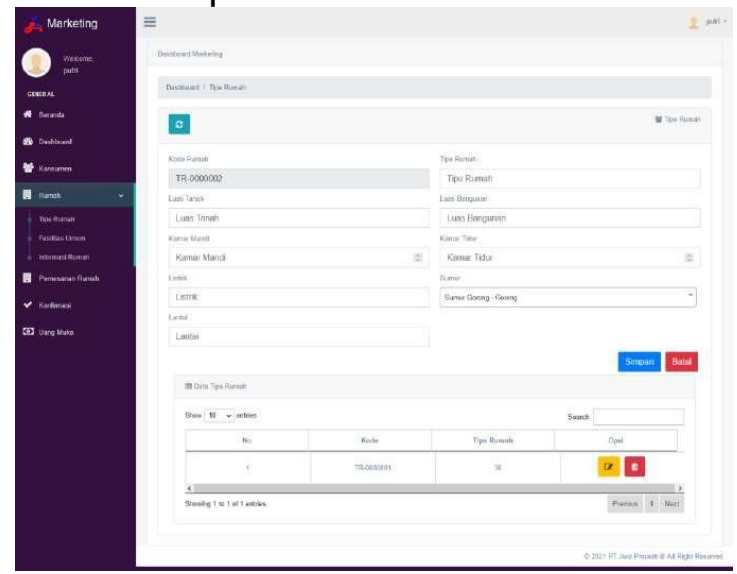

Gambar 14. User Interface Halaman Tipe Rumah 
14. User Interface Halaman Fasilitas Rumah

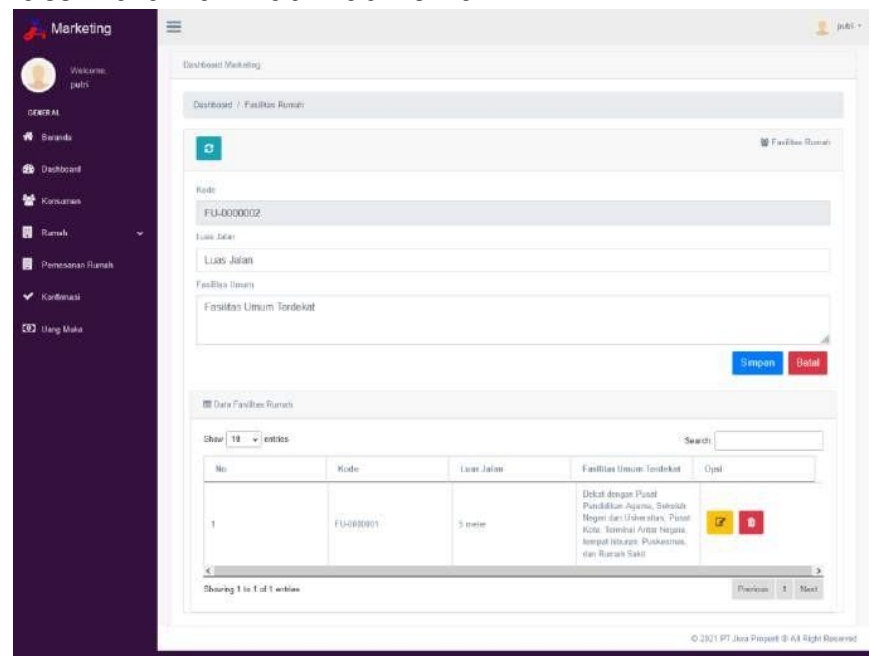

Gambar 15. User Interface Halaman Fasilitas Rumah

15. User Interface Halaman Informasi Rumah

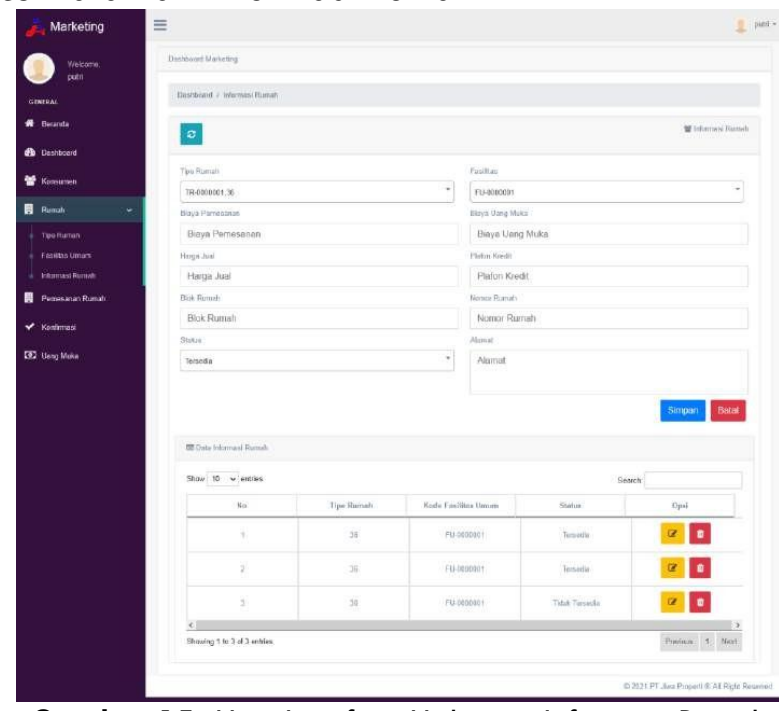

Gambar 15. User Interface Halaman Informasi Rumah

16. User Interface Halaman Pemesanan Rumah

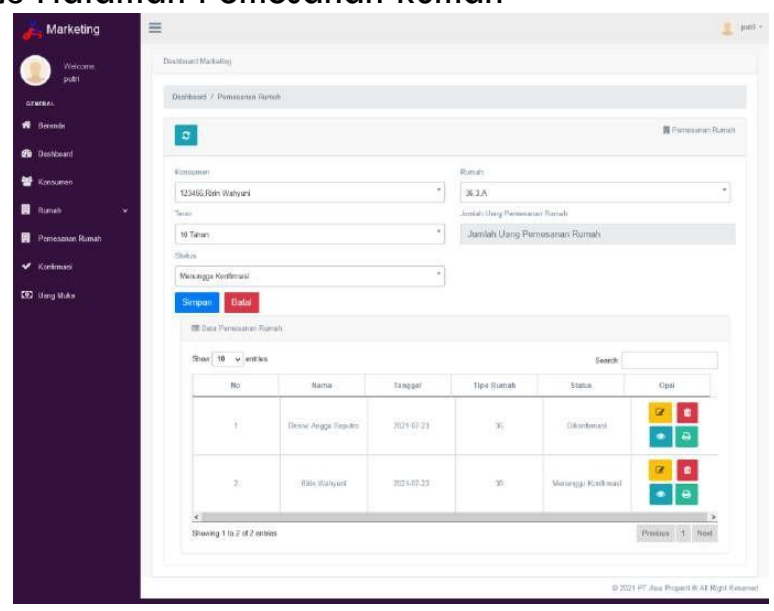

Gambar 17. User Interface Halaman Pemesanan Rumah 
17. User Interface Halaman Preview Data Pemesanan Rumah

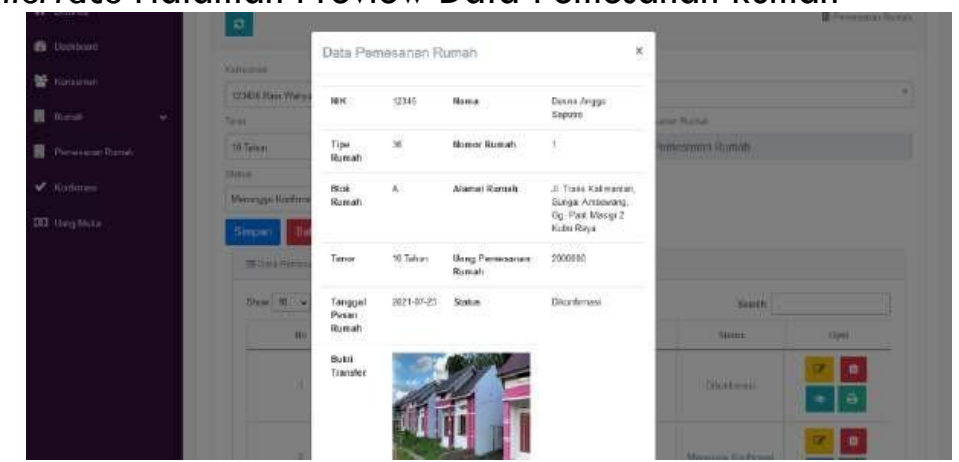

Gambar 18. User Interface Halaman Preview Data Pemesanan Rumah

18. User Interface Kuitansi Pemesanan Rumah

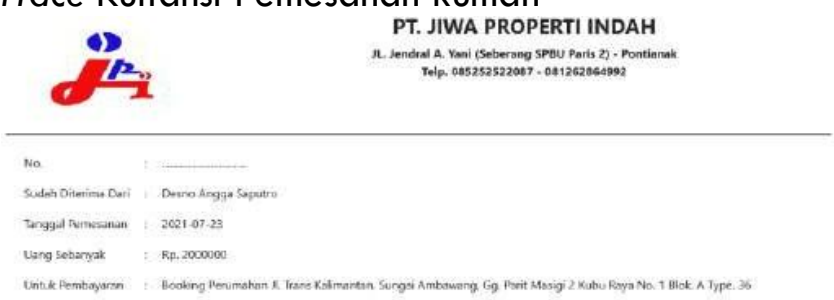

Gambar 19. User Interface Kuitansi Pemesanan Rumah

19. User Interface Halaman Konfirmasi Pemesanan Rumah

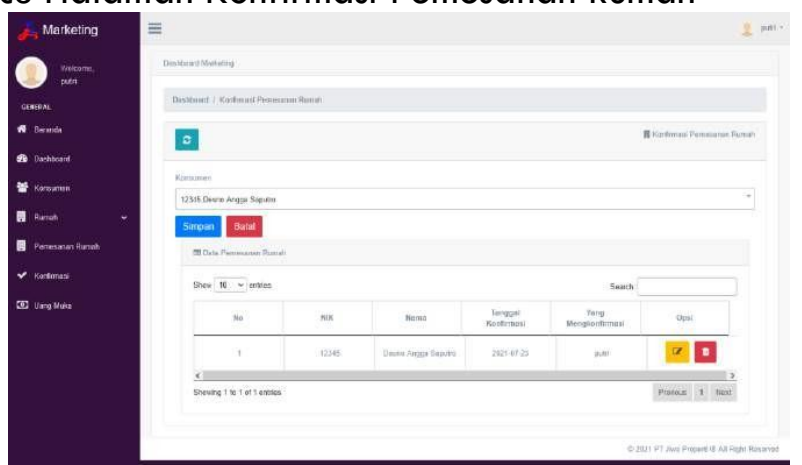

Gambar 20. User Interface Halaman Konfirmasi Pemesanan Rumah

20. User Interface Halaman Data Uang Muka

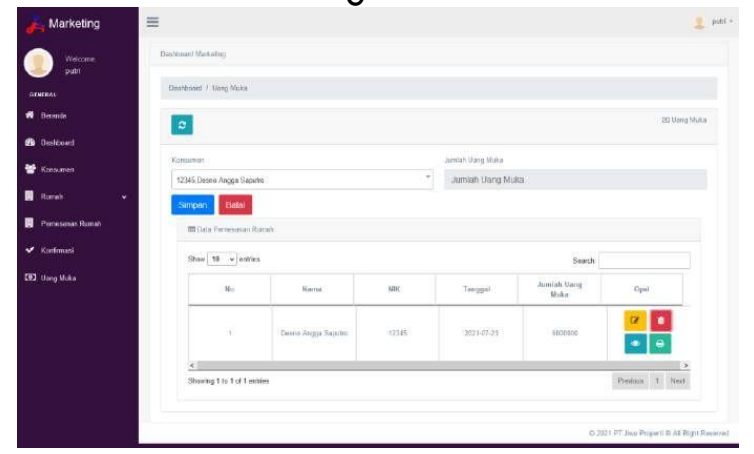

Gambar 21. User Interface Halaman Data Uang Muka 
21. User Interface Halaman Preview Data Uang Muka

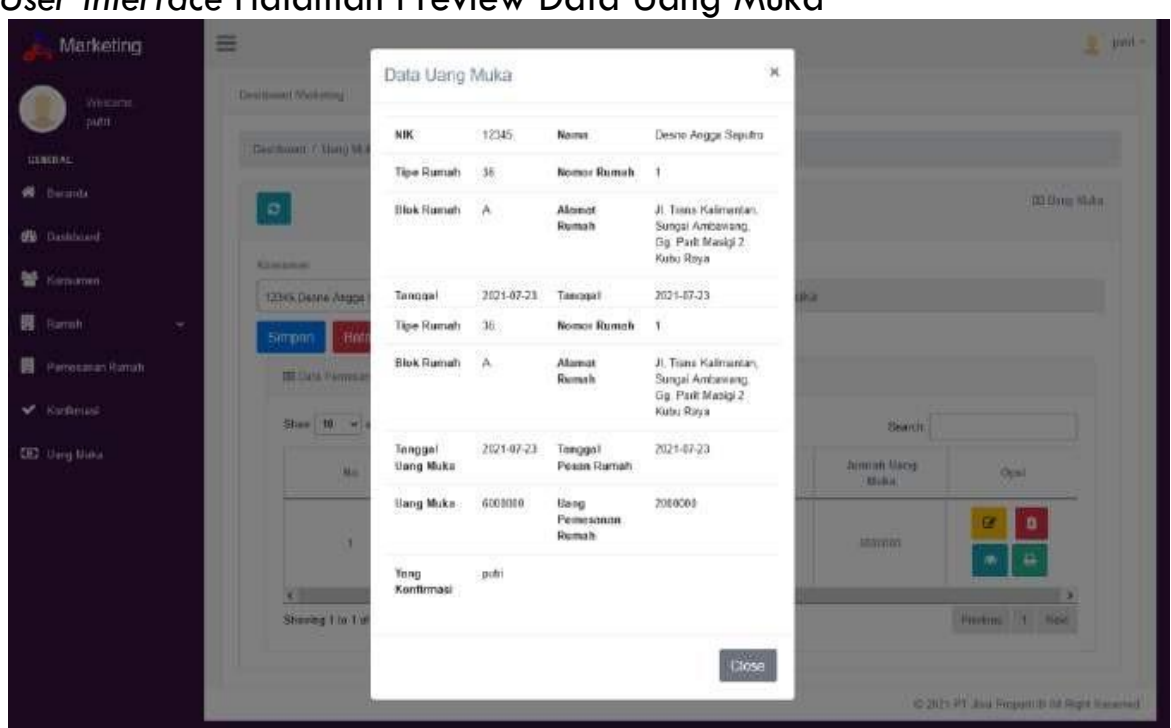

Gambar 22. User Interface Halaman Preview Data Uang Muka

22. User Interface Kuitansi Pembayaran Uang Muka

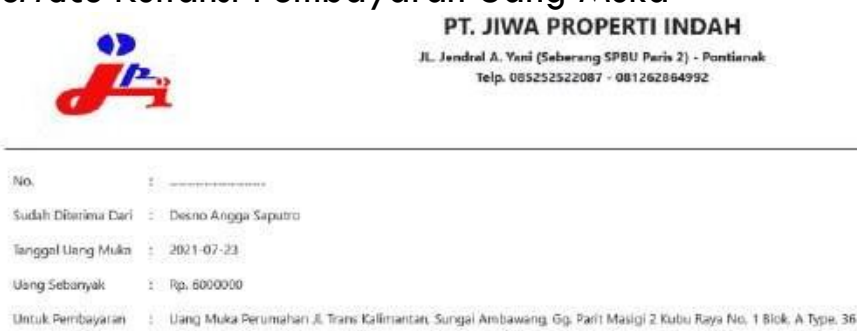

Gambar 23. User Interface Kuitansi Pembayaran Uang Muka

23. User Interface Halaman Beranda Admin Keuangan

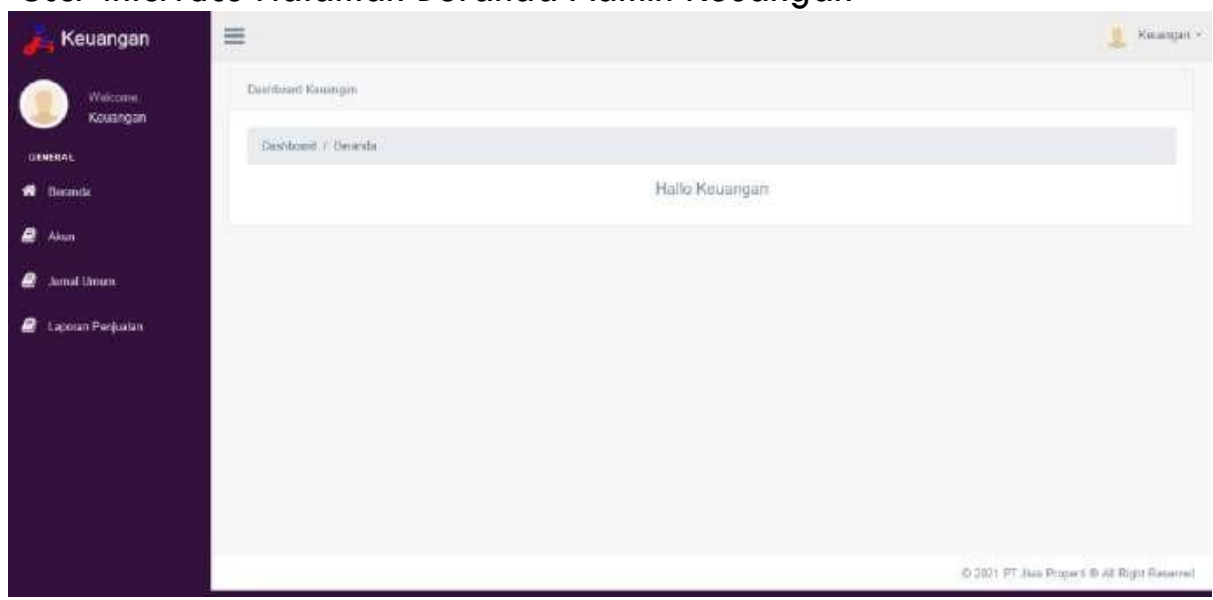

Gambar 24. User Interface Halaman Beranda Admin Keuangan 
Partisipasi mitra terhadap metode \& langkah-langkah pelaksanaan yang dilakukan oleh Tim PM dapat dilihat pada Tabel 1 berikut:

Tabel 1. Partisipasi Mitra

\begin{tabular}{|c|c|c|c|}
\hline No & Permasalahan & Solusi & Partisipasi Mitra \\
\hline 1 & $\begin{array}{l}\text { Pengolahan data pada PT Jiwa } \\
\text { Properti Indah masih } \\
\text { menggunakan sistem manual yang } \\
\text { menyebabkan } \\
\text { keterlambatan dalam } \\
\text { penyusunan laporan karena data } \\
\text { yang diperlukan masih dicatat } \\
\text { dalam buku atau kertas }\end{array}$ & $\begin{array}{l}\text { Pembuat } \\
\text { an } \\
\text { Website }\end{array}$ & $\begin{array}{l}\text { 1. Pendampingan Observasi; } \\
\text { 2. Wawancara dengan Tim } \\
\text { PM; } \\
\text { 3. Penyediaan Ruang } \\
\text { Pertemuan; } \\
\text { 4. Pembahasan Agenda } \\
\text { Pelatihan; } \\
\text { 5. Menjelaskan sistem } \\
\text { berjalan }\end{array}$ \\
\hline 2 & $\begin{array}{l}\text { Belum pernah memiliki aplikasi } \\
\text { website dalam menunjang pekerjaan }\end{array}$ & Workshop & $\begin{array}{l}\text { 1. Meminta dibuatkan modul } \\
\text { atau buku petunjuk } \\
\text { 2. meminta admin diberikan } \\
\text { penjelasan dalam } \\
\text { pengelolaan website }\end{array}$ \\
\hline
\end{tabular}

Secara singkat, hasil pengabdian kepada masyarakat yang dilakukan dapat dilihatpada Tabel 2 berikut :

Tabel 2. Hasil/Kemajuan Yang Diperoleh Mitra

\begin{tabular}{|c|l|l|l|}
\hline No & \multicolumn{2}{|c|}{ Permasalahan Solusi } & \multicolumn{1}{|c|}{$\begin{array}{c}\text { Hasil/Kemajuan Yang } \\
\text { Diperoleh Mitra }\end{array}$} \\
\hline 1 & $\begin{array}{l}\text { Pengolahan data pada PT Jiwa } \\
\text { Properti Indah } \quad \begin{array}{l}\text { masih } \\
\text { menggunakan sistem manual } \\
\text { yang } \\
\text { keterlambatan menyebabkan } \\
\text { penyusunan laporan karena } \\
\text { data yang diperlukan masih } \\
\text { dicatat dalam buku atau kertas }\end{array}\end{array}$ & $\begin{array}{l}\text { Pembuatan } \\
\text { Website }\end{array}$ & Memiliki website resmi \\
\hline 2 & $\begin{array}{l}\text { Belum pernah memiliki aplikasi } \\
\text { website dalam menuniang } \\
\text { pekerjaan }\end{array}$ & Workshop & $\begin{array}{l}\text { Pengelolaan terkomputerisasi } \\
\text { seperti pemasaran, laporan } \\
\text { keuangan, data konsumen }\end{array}$ \\
\hline
\end{tabular}

Kendala yang dihadapi dalam pelaksanaan kegiatan pengabdian kepada masyarakatantara lain:

1. Jangka waktu yang lama dalam pembuatan aplikasi

2. Pada masa pandemi, ada kendala untuk wawancara langsung karenaadanya pemberlakuan PPKM.

3. mengubah mindset mitra terhadap kemudahan sistem infomasi

Dalam rangka mengatasi permasalahan tersebut, maka tim pengabdian kepadamasyarakat melakukan serah terima dokumen Petunjuk Teknis atau modul seperti gambar berikut :
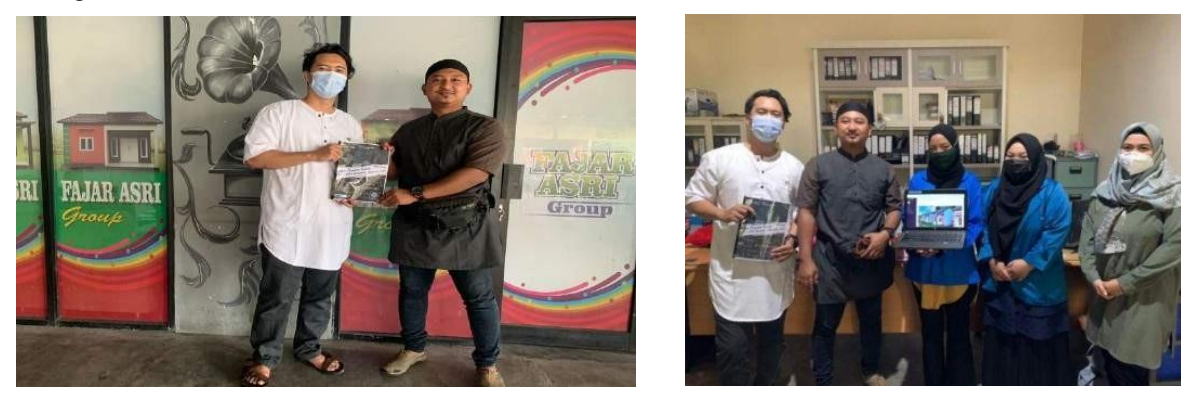
Hasil dari kegiatan ini telah dipublikasikan pada berita nasional dengan link https://www.republika.co.id/berita/r 1 2jby349/dosen-ubsi-latih-pembuatanwebsite-penjualan-rumah

\section{PENUTUP}

PT Jiwa Properti Indah merupakan suatu badan usaha milik swasta yang berdiri dalam bidang perdagangan, real estate dan properti, serta membangun dan menjual perumahan bersubsidi dari pemerintah yang ditujukan untuk masyarakat berpenghasilan rendah. Berdasarkan hasil pengabdian masyarakat dapat disimpulkan bahwa:

1. Aplikasi penjualan rumah ini dapat menjadi salah satu solusi yang bisa digunakan untuk mempermudah dalam mengelolah data penjualan serta dapat membuat laporan penjualan dengan cepat dan efisien.

2. Aplikasi penjualan yang di rancang dapat di akses oleh konsumen, admin marketing, admin keuangan, dan direktur.

3. Pengolahan data pada PT Jiwa Properti Indah masih menggunakan sistem manual yang menyebabkan keterlambatan dalam penyusunan laporan karena data yang diperlukan masih dicatat dalam buku atau kertas. Oleh karena itu, dengan adanya sistem terkomputerisasi dapat memudahkan pengguna dalam melaksanakan pekerjaan dengan cepat dan efisien.

\section{E. UCAPAN TERIMA KASIH}

Terimakasih yang sebesar-besarnya kami ucapkan kepada Universitas Bina Sarana Informatika kampus kota Pontianak serta kepada seluruh tim panitia serta mahasiswa kami yang ikut terlibat sehingga kegiatan ini berjalan dengan lancar. Terima kasih juga kepada Lembaga Penelitian dan Pengabdian Pada Masyaraka (LPPM) Universitas Bina Sarana Informatika (UBSI) atas dukungannya berupa dana kegiatan pengabdian kepada masyarakat ini di PT. Jiwa Properti Indah.

\section{F. DAFTAR PUSTAKA}

A Purba, R., Sudarso, A., Silitonga, P. H., Supitriyani, S., \& Yusmanizar. (2020). Aplikasi Teknologi Informasi: Teori dan Implementasi. Yayasan Kita Menulis.

Al Yakin, A. (2019). Manajemen Kelas di Era Industri 4.0. Journal Peqguruang: Conference Series, 1(2), 9-12. http://journal.lppmunasman.ac.id/index.php/peqguruang/article/view/328

Beben Sutara. (2017). Optimalisasi Aplikasi Transaksi Penjualan Berbasis Web Menggunakan Framework Codeigniter. Jurnal Informatika:Jurnal Pengembangan IT(JPIT), 2(1), 1-5.

Hermawanto, A., \& Anggraini, M. (2020). GLOBALISASI, REVOLUSI DIGITAL DAN LOKALITAS: Dinamika Internasional Dan Domestik Di Era Borderless World (Cetakan Pe). LPPM Press UPN.

Nugraha, W., \& Syarif, M. (2018). Penerapan Metode Prototype Dalam Perancangan Sistem Informasi Penghitungan Volume Dan Cost Penjualan Minuman Berbasis Website. JUSIM (Jurnal Sistem Informasi Musirawas), 3(2), 97-105.

Savitri, A. (2019). Revolusi Industri 4.0: Mengubah Tantangan Menjadi Peluang di Era Disrupsi 4.0. Genesis.

Sidik, F., \& Rahmawati, M. (2018). Perancangan Sistem Informasi Pendaftaran Siswa Baru Berbasis Web Pada SMK Bina Putra Jakarta. Paradigma-Jurnal Komputer Dan Informatika, 20(1), 119-128.

Spurlock, J. (2013). Bootstrap: responsive web development (First Edit). O'Reilly 
Media, Inc.

Suwandi, S. (2019). Mereduksi Benturan Kecerdasan Dalam Pembelajaran Bahasa Indonesia Di Era Revolusi Industri 4.01. Prosiding Seminar Nasional Fakultas Keguruan Dan Ilmu Pendidikan, 1. 